\title{
The Effect of Using the Constructivist Learning Model in Teaching Science on the Achievement and Scientific Thinking of 8th Grade Students
}

\author{
Ahmed O. Qarareh ${ }^{1}$ \\ ${ }^{1}$ Department of Curriculum and Instruction, Tafila Technical University, Jordan \\ Correspondence: Ahmed O. Qarareh, Department of Curriculum and Instruction, Tafila Technical University, \\ Jordan. E-mail: ahmadq@ttu.edu.jo
}

Received: December 10, 2015 Accepted: February 7, 2016 Online Published: June 28, 2016

doi:10.5539/ies.v9n7p178

URL: http://dx.doi.org/10.5539/ies.v9n7p178

\begin{abstract}
The study aims to investigate the effect of using constructivist learning model in teaching science, especially in the subject of light: its nature, mirrors, lens, and properties, on the achievement of eighth-grade students and their scientific thinking.

The study sample consisted of (136) male and female $8^{\text {th }}$ graders were chosen from two basic schools in Tafila in the scholastic year 2015/2016. The four-class sample was divided into two groups (controlled \& experimental).

For achieving the study aims, the researcher prepared lesson plans using constructivist learning model, achievement test and scientific thinking test, which validity and reliability were checked.

To answer the questions of the study, means, SD, ANOVA and ANCOVA were used to determine the differences in means of the groups of the study.

The results show that there is statistically significant difference at $(\alpha=0.05)$ for the effect of the constructivist Learning model on the achievement and scientific thinking in favor of experimental group, and there is no statistically significant difference at $(\alpha=0.05)$ for the constructivist Learning model on the achievement and scientific thinking attributed to gender, and there is no statistically significant difference at $(\alpha=0.05)$ for the dual interaction between teaching method and gender on the achievement and scientific thinking.

In the light of the study results, the researcher presented a number of recommendations including: extra attention should be given to employ constructivist learning model within science courses, and conducting further studies about the effect of the constructivist Learning model on various learning outcomes.
\end{abstract}

Keywords: Constructivist Learning Model, teaching science, achievement, scientific thinking

\section{Introduction}

Globally and locally educational field has witnessed many projects and programs aimed at reforming science education. Some projects such as: Coordination, Sequence and Scope C \& SS appeared in the United States. This initiative was adopted by National Science Teachers Association (NSTA) in 1990; the above project represents an initiative to rebuild the science curriculum depending on the notion that the various natural science subjects share a lot of topics and scientific processes. Therefore, we have to find a method to coordinate between these subjects to enable students to realize how such subjects are interrelated. Then, Biological Science Curriculum Study (BSCS), which resulted in preparing three integrated books in biological sciences for the high school, and Physical Science Study Committee (PSSC), projects (Faqihi, 2009)

The 2061 project provided by the American Association for the Advancement of Science (AAAS) in order to improve science education, that project was based on several principles, namely:

- The adoption of scientific inquiry as part of the nature of science.

- Learner's acquisition of the knowledge and skills necessary to deal effectively with population issues.

- Understanding through the use of scientific study methodology, curiosity, and the use of thinking.

- Attention to the characteristics of the learner, preparing content in line with these characteristics 
- Integrated vision for various subjects of science (Najdi et al., 2005).

Then the movement of interaction among (Science, Technology, and Society) appeared. It refers to the interaction between the three components, and considered one of the best science curricula reform movements that seeks to develop the scientific culture, this movement was developed as a response to the criticism directed to the science curriculum in the fifties and sixties, the omission of the mutual relationship between science and technology, and neglecting the social aspect of science. National Science Education Standards (NSES) have also been developed in the United States, which is the oldest and most prominent building educational standards projects on a global scale and its history is linked to the efforts of the education development and educational reform movement that has cast a shadow on the various fields of education and education system, and on the various aspects of the American society (Zaitoon, 2014).

These projects emphasize the following:

- Focus on the positive learners (students), and their activities to achieve the objectives of the study of science.

- Integration of various subjects of science study.

- Interest in the scientific activity and laboratory studies.

-The promotion of scientific thinking among students and train them to solve problems.

- Training learners on research methods.

- Relate the topics to the needs of the population.

- Take advantage of the technical development in the field of science education.

At the level of the Arab countries, national standards preparing project was released in Egypt in 2003, it included a vision of education experts in Egypt, and their opinions about the educational process in all aspects. In the Arab Gulf States the Supreme Education Council (SEC) in Qatar issued in 2004, the standards for the preparation of curricula for four subjects namely: Arabic, English, science and mathematics identified the general framework for the curricula (Faqihi, 2009).

Jordan witnessed great interest in curriculum development in general and the science curriculum in particular. This interest began with the movement of Educational Development in 1987 and focused on three platforms: the development of scientific thinking, taking into account individual differences, and implementation of knowledge in life, and then followed by the Knowledge Economy Project in 2006 and focused on the following skills: Learn how to learn, communication skills, scientific thinking, leadership and awareness. These movements stressed the need to review all curriculum elements, including the teaching methods that must be focused on the learner. The general framework of the science curriculum for basic stage emphasized the need to choose the teaching methods that give the learner the main role in active learning, develop his thinking skills, communication, and scientific abilities (Ministry of Education, 2012).

Whereas science course is considered a basic subject for education because it involves knowledge that describes, explains and predicts many of the associated scientific phenomena; the teaching of science should focus on the implementation of knowledge in new situations, and the development of mental abilities to face and solve life problems; however, the process of learning and teaching science faces several challenges, including: the idea of memorizing uncorrelated ideas, the lack of investigative activities, and the use of methods of teaching that do not give a role for the learner, not linking learning to education situations, the focus on the information as essential target. Faraj (2000) indicates that science supervisor feels that science teachers focus on the cognitive aspect only and neglect the other aspects.

Therefore, the development of learning and teaching science and overcoming these challenges requires a review of the elements of the education process, especially teaching methods. What learners learn is not enough; we should focus on how they learn. Therefore, stakeholders shall use activities and give learners opportunities to develop their mental and cognitive abilities, attitudes and skills as one of the most important objectives of teaching science, and take advantage of modern theories of teaching and learning of science and the most important one is constructivism theory which was based on several theories including: Piaget's theory of cognitive learning and cognitive development, theoretical knowledge in dealing with the learner's knowledge and the focus on internal factors affecting learning, the social theory in simulation and modeling, and the human theory in focusing on the needs and interests of the learner, and its role in discovery and construction of knowledge, constructivism theory focuses on the prior knowledge that can be used by the learner to understand the new experiences and new information; therefore, learning happens when you change the cognitive structure of learners; and by providing them with new knowledge or reorganization of what they know (Khalili, 1995). 
Constructivism is known as a cognitive theory focuses on the role of the learner in the self-construction of knowledge Glasersfeld (1990) and Jodi and Jula (2002) refer to it as a learning theory offers an explanation of the nature of knowledge and how the learner learns. Zaitoon (2007) refers a process of receiving involves learners' building of new meanings within the context of the current knowledge according to their experiences and learning environment.

It was one of the most important revolutionary theories in the field of education, as it focused on the knowledge and how to provide it to learners in gradual steps, and it receives growing interest in contemporary educational thought, Aqeeli (2005) stresses its importance as a new theory in teaching and learning based on the idea of teaching for understanding, and the adoption of the learner as the center of the educational process; the constructivist teaching is based on the principle that the learner is active and positive.

Constructivism theory is based on three bases as Khataibeh (2008) demonstrates:

1) The meaning is self-built by the cognitive mechanism of the learner, and the (meaning) is not transfer from the teacher to the learner, but created inside the mind of the learner as a result of interaction with the outside world, and definitely influenced by previous experiences.

2) The formation of meanings is a psychological process requires active mental effort.

3) The cognitive structure of the learner is resistant to change

In the light of constructivism theory, the teaching shifts from focusing on external factors to focusing on internal factors that affect learning, such as prior knowledge of the learner, the ability to remember and processing of information, and motivation to learn, and this makes learning meaningful. Zaitoon (2003) indicates that learning in this theory is an ongoing process of building, which is active and purposeful. A structural process means that the learner makes new structures of knowledge or rebuilds compositions or his cognitive system, since the experience of the learner, and prior knowledge have a clear impact on the learning process.

Therefore, every learner has his own way of understanding, as the learning process is not conveyed or copied from the mind of the teacher to the learner's, but must be based on understanding of a meaning. In any process of learning and teaching, it would be essential that the teacher reaches a common understanding with the learner; which means that the learning processes should include negotiation and interpretation to reach this understanding. Being an active process means the learner is making mental effort to gain access to knowledge himself, and being a purposeful process means that learner seeks to achieve certain purposes contribute to solving the problem he faces, answer a question, or satisfy internal tendency, and this underlines the importance of taking the purposes of learning from the learner's a real life, interests and needs.

The assumptions underlie the theory, In general are:

1) Learner is active during the learning process, and this active process leads to the formation of the meaning

2) Prior knowledge of the learner is the focus of attention in the learning process, as he builds knowledge on the light of previous experience.

3) The learning process includes the construction of new meanings or rebuilding and modification of meaning through social negotiation with others

4) Learning is influenced by previous knowledge.

5) Teaching methods that allow the exchange of views and ideas help to explain the phenomena.

6) Investigative activities are helpful when they encourage discussion.

7) Learning cannot occur without a change in the cognitive structure of the learner, as the re-organization of knowledge happens after receiving new knowledge.

8) The best learning occurs when the learner is facing new situations, new tasks and problems.

9) Learner builds knowledge through social negotiation process (Glaserfeld, 2001; Zaitoon, 2003).

Many models have been emerged from the constructivism theory, including: conceptual change model, learning cycle model, problem-based learning model, generative, model, constructivist learning model, and others, all of these models allow the learner active participation in activities to build and organize the knowledge by himself (Mazen, 2009).

Perkins (1991) refers to The Constructivist Learning Model as one of the most important of these models, based on the following grounds:

1) Invite learners to participate in the classroom activities. 
2) Use of the educated concepts and knowledge in guiding the educational situation.

3) Provide an opportunity for learners in the discussion.

4) Prepare questions that motivate learners to return to learning resources.

5) Encourage learners to modify interpretations.

The Constructivist Learning Model focuses on the learner as a center for the learning process, able to build knowledge by himself through the collection of information and data, the formation of hypotheses, access to results and generalizations, discuss solutions, ideas and concepts, and develop them through interaction with others, then apply the findings in new educational conditions and situations.

\section{Steps of the Constructivist Learning Model}

Zaitoon (2007) indicated that constructivist Learning is made up of four complementary stages, which adopted the constructivism theory to ease learner's construction of scientific concepts through mental processes, and each stage is closely linked to the next stage and the stages are:

1-Engagement or Invitation Stage

At the beginning of the educational situation, the teacher engages the learners in the new subject asks them questions in order to invite them to learn, think, motivate them, and create a knowledge-based environment to learn the subject, and figures out their ideas and knowledge necessary to learn a new subject.

\section{2-Exploration Stage}

This stage is the most important in the classroom, where the teacher divides the learners into heterogeneous groups; and each group carries out various activities such as collecting data and information, classifying them, develop hypotheses, ask questions, search for answers and explanations, access to solutions, criticize them, issue judgment ; in preparation for social dialogue to reach solutions to the question raised at the beginning of the class. The teacher here is a facilitator hears and raises additional questions.

\section{3-Explanation Stage}

At this stage learners provide explanations, suggestions, propose solutions, and test the validity of these solutions based on their new experiences, as they build the new knowledge and link it to the previous one, or modify the previous knowledge and perceptions, and the teacher has to encourage learners to formulate their findings, give them enough time to put forward suggestions and interpretations, help learners, and facilitate the learning process.

\section{4-Decision Making Stage (Problem Solving):}

This step involves access to the appropriate solution to the problem and implementation of such solution. Hence the cognitive integration process occurs between the new and previous concepts, which lead to cognitive integration of the concepts and the emergence of more extensive and deeper concepts. Consequently, this resulted in new construction of knowledge at the part of the learners, and application of what they have learned in new situations.

The researcher follows these steps in this study, particularly in the design of educational situations that have been taught (The unit of light).

Yager (1993) confirms that the Constructivist Learning Model has several features:

1) Locate the learner at the center of the educational process, he is active, looks, discovers and implements activities, and has the opportunity to exercise the fundamental and integrated science processes, think scientifically in the largest possible number of solutions to one problem, and he plays the role of scholar.

2) The development of positive trend at the learner towards learning and its processes.

3) Gives the learner the opportunity to debate and negotiate and cooperate, and develop a sound language for dialogue.

4) The Constructivist Learning Model links between science and technology, and the role of science in solving the problems of society.

Many studies have indicated that the use of effective teaching methods provide an effective environment to do the role of the learner and responds to his needs and interests, and motivate the scientific thinking which is seen as the most important educational targets educational process development, and the target of teaching science. The scientific thinking is considered a complex mental process through which the learner can do meaningful 
thing based on the situations he passes through, Jarwan (2005) refers to it as a mode of thinking that supports the scientific method. However, Zaitoon (2014) refers to it as that mental activity used by the individual to address the problems he faces in his life, and to search, explore problems and find solutions.

Attention to scientific thinking has begun because of close relation to scientific and technical development, and reflected on the scientific education that targets the development of inquiry skills and scientific study of learners. The contemporary educational trends emphasize the need for scientific thinking development, as the main report of the US National Science Council stressed the need to develop the learner's capabilities (Qadri, 2005). In Jordan, the Education Act indicates that the main goals of education are the development of thinking skills among students; in order to create the ideal citizen (Ministry of Education, 2012).

Those interested in the science teaching believe that helping students to acquire various scientific thinking skills such as: observation, classification, measurement, conclusion, forecasting, judging, induction, inference, interpretation of data, control of variables, etc., and that practice and application of these skills is one of the fundamental objectives of the scientific education, when acquired by the students, it helps them to cope with renewable life problems, and it should be noted that the advanced industrial countries attention to this goal in their educational programs was a critical factor that helped them to achieve scientific and technological advancement (Abu Jalala.2005).

The Scientific thinking has many features:

1) It is an organized process passes through specific steps beginning with the purposeful note of the phenomenon, and ending with an explanation in the form of hypotheses validated by experiment.

2) A purposeful process with a specific and clear goal.

3) Does not occur in isolation from human, rather, it is a product of mental activity.

Dewey identified the elements of scientific thinking as follows: identify the problem, collect data, develop hypotheses and test their validity, choose the most suitable ones and solve them. This selection of the elements of the scientific thinking agrees with what referred to by the National Society for Studies in Education in America (NSSE), and thus scientific thinking is a mental activity essential in regulating the individual ideas and solve problems facing him in an objective manner, and helps individuals take the decisions that have become one of the main goals of scientific education at the present time (Qadri, 2005).

Educators paid attention to the academic achievement, because of its great importance in the learner's life, it is the result of what happens in the educational institutions of multiple learning and teaching activities resulted from skills, knowledge, trends, tendencies and processes of science, Abu Jado (2003) identifies it as the outcome of what you learn after a period of time, measured by planned tests, According to Jalali (2011) it is the learner's achievement of the highest level of science or knowledge to move from one stage to another for science and knowledge.

Academic achievement was subject of multiple study and studies as efforts tended to look for factors and mental, emotional, and social variables associated with the study achievement - as Multi-Variable Phenomenon - starting from the school and its possibilities, the teacher and the skills and methods of teaching, curriculum, the learner's abilities, trends, and motivation.

Accordingly, the use of Constructivist Learning Model in the teaching of science can contribute to the improvement of student achievement, and the development of their scientific thinking. This study came to investigate the effect of Constructivist Learning Model in student achievement, and their scientific thinking in the field of science.

\subsection{Study Problem}

The study problem came from the researcher's following of teaching science subject, it has been observed that many learners (students) are unable to understand and assimilate the scientific concepts, or employ the scientific knowledge in new situations. Some studies (Kubaisi, 2011; Ministry of Education, 2012) indicated that there is a decline in the learners' achievement in general and in scientific subjects in particular, and in levels of thinking and its different forms; which in turn adversely affect the learner, causing frustration. Osborne, Simson, and Collins( 2003) indicate that large numbers of learners (students) in some countries of the world evade studying science because of their negative attitudes towards it, Zacharia and Barton(2004) confirmed that the scientific capacities of learners (students) and their understanding of the science are the main reasons that may create positive attitudes among learners (students) towards the science, one of the reasons for this is the omission of the role of the learner in the learning process and considering him as a store to accumulate information and 
knowledge, and limiting the learning process to remembering information only, as the method of teaching prevailing often teaching of science depends on the theoretical instructional explanation that neither engage the learners, nor link the new experiences to the previous ones. This prompted those concerned with scientific education to seek methods and strategies for teaching that will help students to understand the science and remove the characteristic of abstraction from the contained concepts, which in turn may lead to the formation of positive attitudes among students towards science.

Based on the above, it is necessary to adapt the teaching method that would help learners learn in an effective manner. This could be done by reconsidering their role in the educational process and considering their active intellectuals that could build their knowledge with their own efforts, and not limiting their role to remembering the accumulated information and knowledge.

\subsection{Study Questions}

1-What is the effect of using Constructivist Learning Model in science teaching on the achievement of eighth-grade students?

2-Is the achievement of eighth grade students who learn by using the Constructivist Learning Model differs from that of their counterparts who use the traditional method of learning depending on gender?

3-Is there an impact on the achievement of eighth-grade students in science attributed to the bilateral interaction between teaching method and gender?

4-What is the effect of using Constructivist Learning Model in science teaching on the scientific thinking of eighth grade students?

5-Is the scientific thinking of eighth grade students who learn by using the Constructivist Learning Model differs from their counterparts who learn by using the traditional method depending on the gender?

6-Is there an impact on the scientific thinking of eighth-grade students in science attributed to the bilateral interaction between teaching method and gender?

\subsection{Study Importance}

The importance of the study lies in the benefits that will come out of the results and from development of educational plans for some topics in science by using the Constructivist Learning Model. The study can also be beneficial for science teachers, supervisors, and science curriculum experts who might include the Constructivist Learning steps in the curricula, and provide feedback to decision-makers in the Ministry of Education to guide teachers towards the modern and most effective methods in teaching science, especially, that it is the first study in the targeted population in which the impact of constructivist model learning in science education on the achievement and scientific thinking is investigated.

\subsection{Study Objectives}

The study aims to investigate the effect of using Constructivist Learning model in teaching science, especially in the subject of light: its nature, mirrors, lens and properties, in the achievement of eighth-grade students and in their scientific thinking.

\subsection{Procedural Definitions}

-The Constructivist Learning Model:

It is a model based on the Constructivism Theory and consists of four stages: engagement, exploring, explanation and interpretations, then the decision making stage, in order to provide the appropriate educational conditions for the learner to be able to build his own knowledge in light topics from the science text book for the eighth grade.

-The Traditional Method:

A teaching method in which the science teacher plays the primary role in teaching, while the role of the learner remains passive in general. In this method, the teacher presents his verbal skills, asks questions to provoke discussion in a specific manner leads to the clarification of other concepts and ideas of the lesson, gives scientific presentation, uses other teaching aids, and uses textbook questions for the purposes of classroom evaluation and homework.

-Achievement:

The result of what the learner learned is an indicator of the effectiveness of the teaching method, and is procedurally measured according to the test result obtained by the learner in the achievement test prepared and 
designed by the researcher for the purposes of this study.

-Scientific Thinking:

A mental activity performed by the learner within specific steps to reach a solution to the problem, and is procedurally measured by according to the test result by the learner in the scientific thinking test applied in this study.

\subsection{Limits \& Determinants of the Study}

This study partly determined by a number of factors including:

1) To what extent the study sample members represent their counterparts from the eighth grade in other schools, especially that this study have been applied to an intentional sample of students taken from four sections in two different schools, in the Directorate of Education in Bsira in the first semester of the academic year 2015 $\backslash 2016$

2) There are two tests in this study, the academic achievement and scientific thinking; and therefore validity and reliability of tests depend on the opinion of the experts selected by the researcher.

3) One of the educators was the science teacher at Bsira Secondary School for Boys, and the other was the science teacher at Qadisiyah Secondary School for Girls. The success of the application depends on the cooperation among the two teachers, principals of the schools, and the researcher.

4) The study addressed the light unit and activities from the science textbook scheduled by the Ministry of Education.

\section{Previous Studies}

A number of relevant studies in various scientific subjects and in different educational outcomes were reviewed, including Akanwa and Ovute ( 2014) study which aimed at investigating the impact of Constructivist Learning Model in teaching physics to secondary school students in Nigeria with regards to achievement and interest, the sample consisted of (160) students, the topics of sound and waves were taught to the two groups: The experimental group by using the Constructivist Learning Model steps, and the control by using the traditional method. Then, the test was applied and the results of the study showed the effectiveness of the Constructivist Learning Model on achievement and interest.

Ahmad (2011) study aimed at investigating the effectiveness of Constructivist Learning in teaching science on the academic achievement and in developing the social skills among the students of the first preparatory grade in Egypt. The results of the study showed statistically significant differences in cognitive achievement and social skills among the study groups in favor of the group that studied science by using Constructivist Learning.

Danial and Bimbola (2010) also studied the effect of using the Constructivist Learning Model on the academic performance of students of the first level at the secondary stage. The study sample consisted of (20) students from southwest Nigeria Schools. The results of the study showed the positive impact of teaching using Constructivist Model on the academic performance.

Gemayel (2010) study aimed to identify the effect of using the Constructivist Learning Model to teach biology on the development of scientific thinking among students of the fourth preparatory grade (tenth year) in Mosul, in Iraq, the study sample consisted of (74) students divided into two equal groups: the experimental group, which studied Constructivist Learning Model, while the control group studied using the traditional method. The researcher adopted the test of scientific thinking strategies, and after applying, results showed that a statistically significant difference between the experimental group and the control group in posttest of scientific thinking and in favor of the experimental group.

Saadi (2010) study investigated the impact of Constructivist Learning Model on the achievement of the fourth scientific grade students (the tenth year) in Biology in schools of Qadisiyah in Iraq. The study sample consisted of (51) students divided into two groups: the experimental group studied using the Constructivist Model, and the control group studied using the traditional method, and the results showed superiority of the experimental group students.

Al Butti and Al Khafaji (2010) study investigated the impact of using Constructivist Learning Model on the achievement of second intermediate grade students, and their attitudes toward physics. The sample consisted of (47) female student distributed into two groups: experimental group consisted of (25) students studied in accordance with the Constructivist Learning, and a control group consisted of (22) students studied according to the traditional method. The two groups were almost similar in age variable, and the previous achievement in science. The two researchers prepared lesson plans, behavioral purposes, and the achievement test, which consisted of 40 items of multiple -choice, and used a scale of attitudes prepared for that purpose. The study 
period took one academic semester, and results showed superiority in both achievement and attitudes towards Physics of the experimental group who studied in accordance with the Constructivist Learning Model compared to the control group who studied in the traditional method.

Hussein (2009) study aimed to find out the effect of using Constructivist Learning Model in the teaching of chemistry on academic achievement and critical thinking among third secondary scientific grade students. The researcher designed the topics of power in chemical reactions using Constructivist Learning Model and in the form of a teacher's guide. The study sample consisted of (120) male and female students from secondary schools distributed to two groups control and experimental. To collect data related to the study, the researcher applied the academic achievement test and critical thinking test. The results showed statistically significant differences between the scores of the two groups in post academic achievement test in favor of students in the experimental group, the presence of statistically significant differences between the scores of male and female students in post academic achievement test in favor of female students, and the presence of statistically significant differences between the scores of the two groups, the experimental and the control in post critical thinking test in favor of the experimental group students, and the presence of statistically significant differences between males and females scores in the post critical thinking test in favor of males.

Hijazi (2009) studied the effectiveness of Constructivist Learning in teaching science on academic achievement and creative thinking among students of the preparatory stage in Egypt. The results of the study indicate the presence of statistically significant differences in achievement and innovative thinking among the study groups in favor of the group that studied science by using the Constructivist Learning.

Abu Naji (2008) investigated the effect of using Constructivist Learning Model in teaching science on academic achievement, and the development of decision-making skills, scientific attitudes among first preparatory grade students. The results of the study showed the effectiveness of Constructivist Learning Model in educational outcomes mentioned above.

Matrafi (2008) study aimed to disclose the effect of using Constructivist Learning Model in teaching science on the achievement and the attitude towards science among third intermediate grade students in Saudi Arabia, the study sample consisted of (132) students from the third-intermediate grade divided into two groups: experimental studied using Constructivist Learning Model, and control studied in the traditional method. The study instruments were represented by the academic achievement test in its three levels: remembering, understanding, application, and the measure of the attitude towards science. Validity and reliability were confirmed, and the study results showed that the experimental group students outperformed their counterparts in the control group in the scores of post academic achievement in all cognitive levels to be measured, and in the attitude toward science as a whole.

Bawi and Khaja (2006) conducted a study aimed to investigate the effect of using Constructivist Learning and Posner models to modify misconceptions of some physics concepts among the students of teacher training institutes in Iraq and their attitudes towards the material. The study sample reached (55) students, (28) students in the first experimental group and (27) students in the second experimental group, the two groups were statistically matched in certain variables: the academic achievement, testing of previous physical information, the IQ test, age, the use of the Constructivist Learning Model in the teaching of the first experimental group, and Posner Model in the teaching of the second experimental group. The experience took one academic semester. The two researchers prepared two instruments: posttest for the physical concepts consisting of (40) items of the (multiple-choice) type, and the scale of the attitude towards physics consisting of (38) items, the two researchers applied the two instruments on the study sample. The results showed a statistically significant difference in modification of the misconceptions of the physical concepts between pre and posttests in the two variables and for both groups, also a statistically significant difference was found between the scores of the two groups of the study and in favor of the first experimental group with regard to the attitude towards physics.

Sharafadean (2008) study identified the impact of teaching physics using Constructivist Learning Model in the development of critical thinking among the second grade secondary students in Sana'a schools in Yemen, and after processing, a test to measure some critical thinking skills was applied including: knowledge of assumptions, interpretation, discussions evaluation, inference, and conclusion. The study results showed the effectiveness of the Constructivist Learning Model in critical thinking skills mentioned above.

Alshaila and Ghaferi (2006) study addressed the effective use of Constructivist Learning Model on the achievement of eleventh grade students in chemistry, and the study sample consisted of (203) students divided into two groups; experimental and control. The study according to the test result verified the equality of the two groups statistically in age, educational level of parents, and intelligence variables. The study took seven weeks, 
and the two researchers applied the achievement test on the study groups. The results showed a statistically significant difference at the level $(0.05)$ between the scores of the two groups and in favor of the experimental group.

Kim( 2005) conducted a study aimed at investigating the effect of the Constructivist Learning Model on the academic achievement and self-concept among sixth grade students in Korea, and the study sample consisted of (76) students distributed into two groups: experimental studied by using the Constructivist Learning Model and conventional studied in the traditional method.

The experiment took nine weeks, and the results of the study confirmed the effectiveness of Constructivist Learning Model on academic achievement while it did not have an impact on self-concept among students

Ajami (2003) study aimed to identify the effectiveness of Constructivist Learning Model and Cognitive Learning Model compared to traditional method with regard to the academic achievement, modification of alternative conceptions, the development of basic science processes, and attitudes towards the study of science among second intermediate grade students. The study sample consisted of (153) female students distributed into three groups from schools of Abha in Saudi Arabia; the first experimental group studied according to the stages of Constructivist Learning Model, the second experimental group studied according to the stages of Cognitive Learning Model, while the control group studied according to the traditional method. To measure the pre and post-performance in the group, the researcher used the following instruments: achievement test, modification of alternative scientific perceptions test, a test in basic science processes, and measure of attitudes towards the study of science.

The study concluded that Constructivist Learning Model had an effect in the development of achievement, and modification of alternative conceptions, and the development of basic science processes, and attitudes towards the study of science.

Allzam (2002) study aimed to identify of the effectiveness of Constructivist Learning Model in science education in the development of academic achievement. The study sample consisted of (112) students including (56) students in the experimental group and (66) students in the control group in two different schools. The researcher used an achievement test to measure students' achievement in scientific concepts, and used (T) test to test differences in means for the experimental and control groups. The study reached the following results, the most important of which: the lack of statistically significant differences between the means of post scores for the students of the experimental group and those of the control group in the achievement at the level of remembering and understanding, While there were statistically significant differences between the means of post scores for the experimental group students and those of control group with regard to the academic achievement at the application level.

Khamisi (2002) study aimed to know the effect of using Constructivist Learning Model and Meaningful Reception Learning in the development of achievement, and skills of science processes, and innovative thinking among the fifth grade students in science. The study sample consisted of (135) students from the fifth grade under the management of Ain Shams education in Cairo, Egypt. The study sample was divided into three groups: the first experimental group, which studied according to Constructivist Learning Model, the second experimental group, which studied according to Meaningful Reception Learning Model, and the control group, which studied in accordance with traditional method used in schools. The study instruments were an achievement test, test of the skills of learning processes, and the innovative thinking test. The researcher used $(\mathrm{T})$ test as a statistical method, and the results of the study showed the effectiveness of the Constructivist Learning Model on the educational outcomes.

Humam and Suleiman (2001) study aimed to identify the impact of the use of the Constructivist Learning Model in the teaching of science in developing concepts and critical thinking. The study sample consisted of (61) male and female students, randomly divided into two groups, the first experimental studied by using the Constructivist manner, and the second a control group and studied laboratory in the traditional method. The applied (T) test and two-method analysis of variance test to find the statistical differences, and the results of the study showed a statistically significant differences in the means of achievements of the students before and after teaching by using the Constructivist Model, and the presence of statistically significant differences in the A means performance of learners in critical thinking test before and after teaching by using the Constructivist Model; which indicates the effectiveness of Constructivist Model in the achievement of the learners and the development of thinking.

The previous studies indicated that there is an the effectiveness for the Constructivist Learning Model in educational outcomes, the researcher has benefited from these studies in the development of lesson planes and 
tests, and the study came -for my knowledge- as the first study in the study population.

\section{Study Methodology}

This part includes a description of study population, sample, instruments, design, and the statistical treatment used in the analysis of the results.

\subsection{Study Population}

The study population consisted of all eighth grade students in the schools of Education Directorate in Bsira in south of Jordan (1302) students, including (642) male students, and (660) female students, distributed into (12) Schools.

\subsection{Study Sample}

Two schools were selected by using the (Available Sample) Bsira Secondary School for Boys, and Qadisiyah Secondary School for Girls because there were more than one section in each of them, and facilitations were provided by the school administrations. The experimental and control groups were selected randomly and Table 1 shows the distribution of the sample according to the teaching method and gender.

Table 1. Sample distribution according to the teaching method and gender

\begin{tabular}{|c|c|c|c|}
\hline Teaching Method Gender & Male & Female & Total \\
\hline Constructivist Learning Model & 34 & 34 & 68 \\
\hline Traditional & 34 & 34 & 68 \\
\hline Total & 68 & 68 & 136 \\
\hline
\end{tabular}

\subsection{Study Instruments}

To achieve the objective of the study the following instruments were used:

First: Lessons plans

Lessons plans have been prepared on light topic: its nature and properties, mirrors, lens, according to the Constructivist Learning Model in its four stages previously mentioned. The subjects were distributed to ten lessons; the duration of each lesson was forty-five. After the completion of the preparation of plans/notes, they were presented to reviewers consisted of faculty members at Jordan Universities and seven eighth-grade science teachers, and were asked to review the plans. A number of the lessons plans were reviewed by deletion, addition or modification. After that step, the lessons planes became ready for application on the experimental group within the classroom, Appendix 1.

Second: Achievement Test

The test aims to measure the achievement of the eighth grade students in the unit of light, the following steps have been followed: Count concepts, principles, laws and theories in the light unit from the science textbook of eighth-grade, and determine the educational goals of the test, and the number was (32) goals, and the preparation of the specification table after determining the weights of the topics included, namely: light, mirrors, lenses, and determine the relative weights of goals according to Bloom's Taxonomy of Objectives: remembering, understanding and comprehension, higher mental processes, and then the formulation of the test items where the test included (32) item in the initial form, each item has four alternatives, only one of them is true, and after writing items.

To verify the validity of the test, the test items were reviewed by reviewers (specialists) some of them hold Doctorate degree in curriculum and methods of teaching science, others hold Doctorate degree in measurement and evaluation and teaching at Jordanian Universities, the reviewers also includes science teachers and supervisors, who hold Bachelor's degree in addition to the Diploma of Education and with long experience in teaching. The total number of reviewers (10), and they were asked to judge the test quality in terms of the representation of the items of the test objectives to be measured, the extent of coverage of the items of the test to the content of the unit, the validity of the language of the items, the accuracy of the formulation of alternatives for each item, and test the suitability of the items to the level of the learners. The referees recommended to modification of (3) items and deletion of (2) items, to become (30) item. 


\section{Test Reliability}

Test reliability means the degree of consistency in the results given by the test if applied on a sample of learners more than once in similar application conditions (Odeh, 2007). The test was applied in its final form on a pilot sample of (30) students, randomly selected from the eighth-grade from outside the study sample, the reliability coefficient was measured using KR-20 Formula, and found to be (0.82) which is suitable and acceptable ratios for the test.

The application of the test on the pilot sample was used to:

1) Calculate the degree of difficulty and discrimination coefficients for each of the items of the test, difficulty ranged between (0.26-0.72), and the mean of difficulty for the whole test (0.49). Melhem (2005) confirmed that the item of difficulty ranging between $(0.25-0.75)$ considered acceptable.

However, discrimination coefficients for test items ranged between (0.25-0.75), and the a means of the whole discrimination coefficients for the test was (0.53), where the test in its final form consisted of (40) items, Appendix 2.

2) Verify the clarity of the meanings of instructions of the test and determine the appropriate time to perform the test.

\section{Third: Scale of Scientific Thinking in Science}

Researcher adopted in his study the scientific thinking scale prepared by Bahjat (2005) after making modification and also benefited from Oleimat, Khawaldeh, and Qadri (2005) scale. In its initial form, the scale consisted of (30) items of multiple choices, distributed on the following skills of the scientific thinking:

1) Identify the problem

2) Put hypotheses

3) Test the validity of the hypothesis:

4) Interpretation

5) Generalization

\section{Validity of Scale}

The validity of this scale has been verified through a presentation to a group of reviewers in curriculum and teaching methods, measurement and evaluation, and physics, and they were asked to judge the appropriateness of scale in terms of the representation of the items of the test of scientific thinking skills, and the validity of items linguistically, and how accurate the formulation of alternatives of each item, and the appropriateness of items to the level of the learners, and the extent of the representation of the items of the target subjects. The reviewers recommended to modification of (4) items, and deletion of (5) items, the test consisted of (25) items.

\section{Reliability of the Scale}

The reliability of the scale was verified by applying to a pilot sample of (30) students from the eighth-grade from outside the study sample, randomly selected by (test- retest). The correlation coefficient reached $(0.81)$, which is suitable and acceptable ratios for the test which encouraged the researcher to apply it in this study in its form, as in Appendix 3.

\subsection{The Study Variables}

The independent variables: teaching method has two levels: Constructivist Learning Model \& the Traditional method, and gender which has two levels: male, female.

Dependent variables: achievement in science, and scientific thinking.

According to the following design:

EG: O1 O2 X O1O2

\section{CG: $\mathrm{O} 1 \mathrm{O} 2$ - $\mathrm{O} 1 \mathrm{O} 2$}

EG: the experimental group, CG: control group, O1: achievement test, O2: test of scientific thinking, $\mathrm{X}$ : the experimental treatment (teaching using Constructivist Learning Model).

\subsection{Statistical Analysis}

The researcher has conducted statistical analysis of the study data by using the following statistical methods:

A. means and standard deviations. 
B. Analysis of variance (ANOVA) to check of equivalence study groups.

C. Analysis of variance (ANCOVA) to answer questions about the study.

\section{Results}

At the beginning, the equivalence of sample groups was checked on the both tests: achievement in science and scientific thinking by calculate the means and standard deviations for students' scores in the prior data, as Table 2 shows.

Table 2. Means and standard deviations for the students' scores on prior achievement test

\begin{tabular}{cccc}
\hline Teaching Method & Gender & Means & Standard Deviation \\
\hline \multirow{3}{*}{ Constructivist Learning Model } & Male & 9.74 & 5.57 \\
& Female & 10.04 & 5.02 \\
& Total & 9.89 & 5.38 \\
\hline \multirow{2}{*}{ Traditional } & Male & 9.44 & 5.77 \\
& Female & 10.88 & 6.03 \\
& Total & 10.16 & 6.01 \\
\hline
\end{tabular}

The difference between the means of the two groups was clear, and to find out whether the differences between the means are statistically significant, the analysis of variance $(2 \times 2)$ was used, and Table 3 summarizes the results.

Table 3. Analysis of variance (2x2) for students' score on prior achievement test according to the variables of teaching method and gender

\begin{tabular}{cccccc}
\hline Source of Variation & $\begin{array}{c}\text { Sum of } \\
\text { squares }\end{array}$ & $\begin{array}{c}\text { degree of } \\
\text { Freedom }\end{array}$ & $\begin{array}{c}\text { Mean } \\
\text { squares }\end{array}$ & F-ratio & $\begin{array}{c}\text { Statistical } \\
\text { Significance }\end{array}$ \\
\hline Teaching Method & 3.679 & 1 & 3.679 & 0.164 & 0.676 \\
Gender & 10.529 & 1 & 10.529 & 0.470 & 0.610 \\
$\begin{array}{c}\text { Interaction between "Teaching } \\
\text { Method \& Gender" }\end{array}$ & 0.031 & 1 & 0.031 & 0.001 & 0.812 \\
Error & 2960.647 & 132 & 22.429 & & \\
Total & 2974.886 & 135 & & & \\
\hline
\end{tabular}

Table 3 shows that there were no statistically significant differences at the level of significance $(\alpha=0.05)$ between the means of students' score in the prior achievement attributed to the teaching method, also there were no statistically significant differences at the level of significance $(\alpha=0.05)$ between the means of students' score in the prior achievement attributed to the gender, and there were no statistically significant differences at the level of significance $(\alpha=0.05)$ between the means of students' score in the prior achievement attributed to the interaction between teaching method and gender, which indicates that the students in the experimental and control groups are equal in the prior achievement.

Also the means and standard deviations for the students' score of the study sample in prior scientific thinking test were calculated, as Table 4 shows. 
Table 4. Means and standard deviations for the students' scores on prior scientific thinking test

\begin{tabular}{cccc}
\hline Teaching Method & Gender & Means & Standard Deviation \\
\hline \multirow{3}{*}{ Constructivist Learning Model } & Male & 6.35 & 2.98 \\
& Female & 6.71 & 3.23 \\
& Total & 6.53 & 3.11 \\
& Male & 6.38 & 3.35 \\
Traditional & Female & 6.59 & 3.87 \\
& Total & 6.48 & 3.65 \\
\hline
\end{tabular}

The difference between the means of the two groups was clear, and to find out whether the differences between the means are statistically significant, the analysis of variance $(2 \times 2)$ was used, and Table 5 summarizes the results.

Table 5. Analysis of variance $(2 \times 2)$ for the students' scores on prior scientific thinking test according to the variables of teaching method and gender

\begin{tabular}{cccccc}
\hline Source of Variation & Sum of squares & Degree of Freedom & Mean Squares & F-ratio & Statistical Significance \\
\hline Teaching Method & 0.064 & 1 & 0.064 & 0.011 & 0.920 \\
Gender & 2.721 & 1 & 2.721 & 0.490 & 0.474 \\
Interaction & 0.175 & 1 & 0.175 & 0.031 & 0.736 \\
Error & 738.009 & 132 & 5.590 & & \\
Total & 740.969 & 135 & & & \\
\hline
\end{tabular}

Table 5 shows that no statistically significant differences at the level of significance $(\alpha=0.05)$ between the means of students' score in the prior scientific thinking attributed to the teaching method, and that there were no statistically significant differences at the level of significance $(\alpha=0.05)$ between the A means of students' score in the prior scientific thinking attributed to the gender, and that there were no statistically significant differences at the level of significance $(\alpha=0.05)$ between the means of students' score in the prior scientific thinking attributed to the interaction between teaching method and gender, that indicates the students in the experimental and control groups are equal in the prior scientific thinking.

Regarding the results of the following questions:

1) What is the effect of using Constructivist Learning Model in science teaching on the achievement of eighth-grade students?

2) Is the achievement of eighth grade students who learn by using the Constructivist Learning Model differs from that of their counterparts who use the traditional method of learning depending on gender?

3) Is there an impact on the achievement of eighth-grade students in science attributed to the bilateral interaction between teaching method and gender?

To answer these questions the means and standard deviations for the students' score on the post achievement test were calculated according to teaching method and gender variables: as Table 6 shows. 
Table 6. Means and standard deviations for the students' score on post achievement test

\begin{tabular}{cccc}
\hline Teaching Method & Gender & A means & Standard Deviation \\
\hline \multirow{3}{*}{ Constructivist Learning Model } & Male & 27.88 & 3.01 \\
& Temale & 23.71 & 2.99 \\
& Total & 25.79 & 3.00 \\
Traditional & Male & 23.59 & 4.02 \\
& Female & 22.54 & 4.32 \\
& Total & 23.06 & 4.17
\end{tabular}

Table 6 shows that difference in means and standard deviations of the students' score, and to find out whether the differences between the means are statistically significant, the analysis of variance $(2 \times 2)$ two-method ANCOVA was used, and Table 7 summarizes the results.

Table 7. Analysis of variance (ANCOVA) (2x2) for students' scores on post achievement test according to the variables of teaching method and gender

\begin{tabular}{cccccc}
\hline Source of Variation & $\begin{array}{c}\text { Sum of } \\
\text { squares }\end{array}$ & $\begin{array}{c}\text { Degree of } \\
\text { Freedom }\end{array}$ & $\begin{array}{c}\text { Mean } \\
\text { Squares }\end{array}$ & F-ratio & $\begin{array}{c}\text { Statistical } \\
\text { Significance }\end{array}$ \\
\hline Prior & 330.653 & 1 & 330.653 & 18.73 & 0.000 \\
Teaching Method & 1120.302 & 1 & 1120.302 & 63.47 & 0.000 \\
Gender & 13.488 & 1 & 13.488 & 0.764 & 0.314 \\
$\begin{array}{c}\text { Interaction between teaching } \\
\text { method \& gender }\end{array}$ & 11.696 & 1 & 11.696 & 0.66 & 0.502 \\
Error & 2312.294 & 131 & 17.65 & & \\
Total & 3788.433 & 135 & & & \\
\hline
\end{tabular}

Table 7 shows statistically significant differences at the level of $(\alpha=0.05)$ between the means of students' score on the post achievement attributed to the teaching method (Constructivist Learning Model, Traditional Method), as the (F) value calculated was (18.730) which is statistically significant at the level of significance $(\alpha=0.05)$, also the results in Table 7 shows no statistically significant differences at the level of $(\alpha=0.05)$ between the means of students' score attributed to the gender, the results also show no statistically significant differences at the level of $(\alpha=0.05)$ between the means of students' score attributed to the effect of interaction between the teaching method and gender.

Regarding the results of the following questions:

-What is the effect of using Constructivist Learning Model in science teaching on the scientific thinking of eighth-grade students?

-Is the scientific thinking of eighth grade students who learn by using the Constructivist Learning Model differs from their counterparts who learn by using the traditional method, depending on the gender?

-Is there an impact on the scientific thinking of eighth-grade students in science attributed to the bilateral interaction between teaching method and gender?

To answer these questions the means and standard deviations for the students' score on the scientific thinking test were calculated according to teaching method and gender variables as Table 8 shows. 
Table 8. Means and standard deviations for students' scores of the study sample in post scientific thinking test

\begin{tabular}{cccc}
\hline Teaching Method & Gender & A means & Standard Deviation \\
\hline \multirow{3}{*}{ Constructivist Learning Model } & Male & 14.12 & 3.78 \\
& Female & 16.59 & 4.23 \\
& Total & 15.35 & 3.24 \\
& Male & 11.56 & 5.48 \\
Traditional & Female & 12.24 & 4.09 \\
& Total & 11.90 & 3.78 \\
& Male & 12.84 & 3.57 \\
Total & Female & 16.00 & 4.10 \\
& Total & 13.62 & 3.91 \\
\hline
\end{tabular}

Table 8 shows difference in means and standard deviation in the scores of students in the study sample in post scientific thinking test, and to find out whether the these differences are statistically significant, analysis of variance ANCOVA ( $2 \times 2)$ was used, and Table 9 summarizes the results:

Table 9. Analysis of variance (ANCOVA) for students' scores on scientific thinking test according to teaching method and gender variables

\begin{tabular}{cccccc}
\hline Source of Variation & $\begin{array}{c}\text { Sum of } \\
\text { squares }\end{array}$ & $\begin{array}{c}\text { Degree of } \\
\text { Freedom }\end{array}$ & $\begin{array}{c}\text { Squares A } \\
\text { means }\end{array}$ & $\begin{array}{c}\text { Calculated F } \\
\text { Value }\end{array}$ & $\begin{array}{c}\text { Statistical } \\
\text { Significance }\end{array}$ \\
\hline Prior & 560.455 & 1 & 560.455 & 73.511 & 0.000 \\
Teaching Method & 400.109 & 1 & 400.109 & 52.980 & 0.000 \\
Gender & 61.261 & 1 & 61.261 & 8.030 & 0.005 \\
$\begin{array}{c}\text { Interaction between } \\
\text { teaching method \& gender }\end{array}$ & 23.162 & 1 & 23.162 & 3.040 & 0.080 \\
Error & 998.810 & 131 & 7.624 & & \\
Total & 2043.897 & 135 & & & \\
\hline
\end{tabular}

Table 9 shows statistically significant differences at the level significance $(\alpha=0.05)$ of between the A means of students' scores on the post scientific thinking attributed to the teaching method (Constructivist Learning Model, Traditional Method), as the (F) value calculated was (73.511) which is statistically significant at the level of significance $(\alpha=0.05)$. And results in Table 6 shows no statistically significant differences at the level of $(\alpha=0.05)$ between the a means of students' scores on the post scientific thinking attributed to the gender, results also show no statistically significant differences at the level of $(\alpha=0.05)$ between the a means students' scores on the post scientific thinking attributed to the effect of interaction between the teaching method and gender.

\section{Discussion and Conclusion}

The results of the study indicated that there is an effectiveness for using Constructivist Learning Model in the achievement of learners in science, and that could be attributed to the fact that learning by using the steps of Constructivist Learning Model helps learners to identify the strength and weakness in their prior knowledge, and through the questions that enable the teacher to identify previous knowledge. This would come as a result of Engagement stage when the teacher, at the beginning of the educational situation, engages the students in the new subject by asking them questions in order to motivate them to learn, think, and to figure out the ideas and knowledge necessary for learning a new subject.

H. Zaitoon and K. Zaitoon (1992) indicates that the learner practiced a kind of mental activity represented in reorganization, arrangement and conversion, which the learner enters to learning material, and represents the material to be learned in the cognitive compositions he has to create new cognitive structures or what is called the formation of knowledge; and so cognitive growth occurs,; as knowledge is not received mainly but built in a 
positive process. It is an adaptive process occurs through the learner's organization of experience through learning from the environment, and hence the learning is meaningful which increases the ability of the learner.

Constructivist Learning Model is also interested in the content to be learned, in terms of organization and arrangement according to the cumulative concepts; which eases the integration of concepts in cognitive structure. Diab (2002) confirms that the role of the teacher is to reveal what goes on the mind of the learner, and in this regard, (Chin) 1996 adds that teaching according to Constructivist Learning is one of the best types of teaching; because it has changed teacher's concepts about learning and teaching, and the imposed on the constructivist teacher new roles from the Directive teacher with Authority to the role of the Constructivist, Interactive, Negotiation, and Facilitator of learning, leading to improved performance of the learners.

Moreover, teaching by using the Constructivist Learning Model gives better opportunities for the learner to participate actively in the teaching-learning process, it has been shown through classroom observations of the researcher, that the experimental group students have shown enthusiasm towards work to learn, and made an effort to acquire knowledge from various sources in order to achieve equilibrium in knowledge when exposed to the lack of equilibrium in the cognitive structure, as well as providing sufficient time for the learner to build his knowledge and apply this knowledge in real situations and authentic tasks.

The results also showed that there are no differences regarding students' achievement attributed to the gender and interaction between genders and teaching method, this is due to the fact that the students have the same environment according to teachers' qualification, subject, schools and tests.

The results of the study also confirmed the effectiveness of the Constructivist Learning Model in the development of scientific thinking, because the learner is given the opportunity to practice thinking skills such as: observation, description, classification, and the conclusion, in addition to developing hypotheses and testing them. It also gives him the opportunity to debate and discuss with colleagues and mentor; which helps him receive training on these skills and master them, through teaching by using the Constructivist Learning Model in its different stages. For example, in the Exploring stage, the learners performs a variety of activities such as collecting data and information, classifying and developing hypotheses, asking questions and searching for answers, providing explanations and getting access to solutions, criticizing and judging them, and reaching solutions for questions asked to them at the beginning of the educational situation.

This helps to develop their scientific thinking, moreover, Explanation stage includes proposing solutions, and testing the validity of these solutions, and finally at the stage of decision-making they reach the appropriate solution to the problem and they implement it., which leads to the formation of new cognitive constructivist, and apply what they have learned in new situations, and this all lead to the development of scientific thinking they have, and make the acquired scientific knowledge fertile ground to solve problems and reach solutions.

Maximus (2003) indicates that the Constructivist Learning Model gives the opportunity for learners to think about the largest possible number of solutions for one problem; which enrich thinking and develop thoughts and opinions, through the organization of learning situations in the form of problems affecting the lives of the learner and contribute to make learning meaningful,. The model takes into account the mental capacity among the educated, and (Wheatly, 1991) adds that teaching using the Constructivist Learning Model provides content in the form of educational tasks; as the learner makes mental effort to get to know, thus Constructivist moves learners from Rote memorization of facts, concepts and scientific principles to self-understanding, which explains what is happening and predicts it.

As it focuses on the learner's effort and his responsibility towards what he learns to build knowledge. However, the role of the teacher is the organizer and manger of the learning environment, receptive to students and their initiatives. The teacher also encourages dialogue, discussions, scientific debates, and tries to satisfy the learner's needs and curiosity.

The results also showed that there aren't differences regarding students' scientific thinking attributed to the gender and interaction between genders and teaching method, this is due to the fact that the students have the same environment according to teachers' qualification, subject, schools and tests.

The results of this study agreed with the most results of the previous lecture such as the study of Akanwa and Ovute (2014), Danial and Bimbola (2010), Hussein (2009) and Hijazi (2009) on the effect of constructivist Learning Model on various learning out comes.

\section{Recommendations}

The researcher recommended using Constructivist Learning Model on science teaching, and should be conducted further studies about the effect of constructivist learning model on other learning out comes. 


\section{References}

Abu Naji, M. (2008). The effect of using constructivist learning model in teaching science on the achievement, and the development of decision-making skills, and scientific attitudes among first preparatory students, Journal of the College of Education, Assiut University, 23(1), 30-79.

AbuJado, S. (2003). Educational Psychology. Amman: Dar Almaseera for publishing, distribution.

AbuJalala, S. (2005). New in the teaching of science experiments in the light of contemporary teaching strategies. Kuwait: Al-Falah Library for publishing and distribution.

Ahmad, M. (2011). The effect of using constructivist learning model in the training of science on the cognitive achievement and the development of social skills among first preparatory graders, Educational Journal, $3(6), 34-55$.

Ajmi, L. (2003). Effectiveness of constructivist \& cognitive models in developing academic achievement and modifying alternative perceptions and developing the basic science processes and attitudes towards science among second intermediate graders (Unpublished PhD thesis). College of education for girls, Riyadh, Saudi.

Akanwa, U., \& Ovute, A. (2014). The effect of Constructive Teaching model on SSS Physics Students Achievement and Interest. Journal of Study and Method in Education, 4(1), 35-38.

Al Butti, J., \& Al-Khafaji, S. (2010). The effect of using constructivist learning methods in the achievement of second intermediate grade students and their attitudes toward physics. Journal of the Faculty of Education, University of Dhi Qar, 2(2), 30-54.

Allzam, I. (2002). Effectiveness of constructivist learning model in learning and teaching science in the intermediate stage (Unpublished master thesis). College of Education, Riyadh, King Saud University.

Alsaila, Al \& Ghaferi, A. (2006). Effective use of constructivist learning model on the achievement of secondary students in chemistry in the Sultanate of Oman. Educational Journal, 20(78) 63-78.

Aqeeli, A. (2005). Theoretical and applied trends for Arabic language teachers in the city of Riyadh and their relationship to the theory of constructivism, Educational Journal, 19(76), 45-62.

Badri, F. (2012). The impact of the constructivist learning model in the practical chemistry on the achievement and the development of scientific thinking among Umm al-Qura University students. An Arab study in education and psychology.

Baimbola, O., \& Daniel, O. (2010). The constructivist based teaching strategy on academic performance of student in integrated science at the junior secondary school level. Educational Study and Reviews, 5(7), 347-353.

Bawi, M., \& Khaji, T. (2006). The effect of using constructivist learning \& Posner models to modify misconceptions of some physics concepts in teacher training colleges' students and their attitudes toward the material. Journal of humanities, 3(27), 33-52.

Chin, C. (1996). The Interrelationship between junior school students scientific epistemological beliefs, learning environment, performance and their cognitive strategy outcomes. DAI, 34(7), 3342-A.

Diab, A. (2002). Constructivism in teaching. Amman: UNRWA.

Faqihi, Y. (2009). Programs and projects for the reform of learning and teaching of Biology. Journal of Knowledge, 4(7), 22-35.

Faraj, M. (2000). Extent to which science curriculum content of intermediate stage in Saudi Arabia addresses dimensions of science and process and the extent of students' understanding of it. Journal of Scientific Education, 3(2), 42-55.

Gemayel, G. (2010). The effect of using the constructivist learning model to train statistics in the development of scientific thinking among the students of the fourth year. The Journal of Education, 17(2), 249-284.

Glasersfeld, V. (1990). An Exposition of cnstructivism: Why some like it radical. Journal for Study in Mathematics Education, 4(6), 102-116.

Glasersfeld, V. (2001). Cognition, Construction of knowledge and Teaching Synthesis, 80,121-140.

Hijazi, A. (2009). The effect of constructivist learning in the teaching of science on the development of achievement and the creative thinking among preparatory stage graders. Journal of College of Education, 
4(8), 56-81.

Humam, A., \& Suleiman, K. (2001). The effect of using constructivist learning model in teaching science to the development of some of the scientific concepts and critical thinking for Second Prep students. Journal of College of Education, 15(2), 54-62.

Hussein, U. (2009). The effect of using constructivist learning model in the teaching of chemistry on the achievement and critical thinking among secondary school students (Unpublished $\mathrm{PhD}$ thesis). University of Sudan for Science and Technology, Sudan.

Jalali, L. (2011). Academic achievement. Amman: Dar Almaseera for publishing, distribution, and printing

Jarwan, F. (2005). Teaching thinking: concepts and applications (2nd ed.). Amman: Dar al fikr for printing, publishing and distribution.

Judi, H., \& Julia, M. (2002). Four Case Studies of Perspective Science, Teachers Concerning Constructivist Teaching Practices. Science Education, 86(6), 783-802. http://dx.doi.org/10.1002/sce.10038

Khalili, K. (1995).Contents of constructivist philosophy in teaching science. Qatar: National Commission for Education, Culture and Science.

Khamisi, M. (2002). The effect of using constructivist learning model \& meaningful reception learning in the development of achievement and skills of science processes and innovative thinking among fifth graders in science (Unpublished $\mathrm{PhD}$ thesis). College of girls, Ain Shams University, Egypt.

Khataibeh, A. (2008). Science Education for All. Amman: Dar Almaseera for publishing, distribution, and printing.

Kim, J. (2005). The effect of constructive teaching approach on students' academic achievement, sell concepts and learning strategies. Asia Pacific Education Review, 6(1), 7-19. http://dx.doi.org/10.1007/BF03024963

Kitami, Y. (2002). General Psychology. Amman: Dar al fikr for printing, publishing and distribution.

Kubaisi, A. (2011). The effect of using constructivist learning model on the achievement of intermediate stage in mathematics and systematic thinking. Basrah Journal for humanities, 32(1), 106-126.

Matrafi, G. (2007). The effect of using constructivist learning model in teaching science on the achievement and attitude towards the subject among the third-intermediate students (Unpublished $\mathrm{PhD}$ thesis). King Saud University, Riyadh.

Maximus, W. (2003). Constructivism in the processes of teaching and learning of mathematics. Workshop presented to Third Arab Conference on systemic approach in teaching and learning, Ain Shams University, Egypt.

Mazen, H. (2009). Cognitive Constructivist. Retrieved from http//hosamma2en.blogspot.com

Ministry of Education. (2009). General framework of science curriculum for basic stage. Amman: national press.

Ministry of Education. (2012). Statistical report of the national test. Amman: National Press.

Najdi, A. et al. (2005). Modern science teaching trends in the light of international standards. Cairo: Dar Alfeker.

Odeh, A. (2005). Measurement and Evaluation. Irbid: Dar El amal.

Oleimat, A., Khawaldeh, S., \& Qadri, S. (2008). The development of scale for scientific thinking skills for secondary school students, Damascus University. Journal of Education and Psychology, 24(2), 235-256.

Osborne, J., Simson, S., \& Collins, S. (2003). Attitudes towards Science: a review of the literature and its implications. International Journal of Science Education, 25(9), 1049-1079. http://dx.doi.org/10.1080/0950069032000032199

Perkins, D. (1991). Technology meets constructivism. Educational Technology, 31(9), 19-21.

Qadri, S. (2005). The development of scale for scientific thinking skills to the level of university students. Journal of Educational Studies, 23(1), 31-40.

Saadi, N. (2010). The effect of using constructivist learning model on the achievement of fourth-grade students in biology. Qadisiyah Journal of Arts and Science Education, 9(3) 243-255.

Sharaf, D. (2008). The impact of teaching physics using constructivist learning model in the development of critical thinking among second secondary students (Unpublished master thesis). University of Sanaa, 
Yemen.

Wheatly, G. (1991). Constructivist perspective on science mathematic learning. Science Education, 75(1), 9-21. http://dx.doi.org/10.1002/sce.3730750103

Yager, R. (1991). The constructivist learning model, towards real reform in science education. The Science Teacher, 58(6), 52-57.

Yager, R. (1993). The Constructivist learning Mode. Science Teacher, 9(2), 52-59.

Zacharia, Z., \& Barton, A. (2004). Urban Middle-school Students' Attitudes toward a Defined Science. Science Education, 88(2), 197-222. http://dx.doi.org/10.1002/sce.10110

Zaitoon, A. (2007). Constructivism theory and strategies of teaching science. Amman: Dar al Shorook for publication and distribution.

Zaitoon, A. (2014). Science teaching methods. Amman: Dar al Shorook for publication and distribution.

Zaitoon, H., \& Zaitoon, K. (1992). Constructivism, from epistemological \& educational perspective. Alexandria: Ministry of Education.

Zaitoon, K. (2003). Learning \& teaching from the perspective of constructivist (1st ed.). Cairo: World of Books.

\section{Copyrights}

Copyright for this article is retained by the author(s), with first publication rights granted to the journal.

This is an open-access article distributed under the terms and conditions of the Creative Commons Attribution license (http://creativecommons.org/licenses/by/3.0/). 